\title{
Pigeons match location of sample more accurately than color of sample
}

\author{
DONALD M. WILKIE, W. J. JACOBS, and RICHARD TAKAI \\ University of British Columbia, Vancouver, British Columbia, Canada
}

\begin{abstract}
Pigeons received delayed-matching-to-sample trials in which the samples consisted of a compound of color and location (red on left key, green on right key). The comparisons were either red and green on the right and left keys (location of color counterbalanced over trials) or two yellow keys. On red-green comparison trials, choice of the matching color was reinforced; on yellow comparison trials, choice of the key that matched the sample location was reinforced. Matching accuracy on location trials exceeded that on color trials both during acquisition (Experiment 1) and when the delay interval was varied (Experiment 2). A control experiment (Experiment 3) demonstrated that this superiority was not due to the presence of location competition on color test trials but not color competition on location test trials. These results, in conjunction with other recent reports in the literature, suggest that control by the elements of a compound sample is often asymmetrical.
\end{abstract}

Short-term remembering in animals frequently is studied with the delayed-matching-to-sample (DMTS) paradigm. Trials start with the brief presentation of one of a set of sample stimuli. Sample presentation is followed by a delay (i.e., a retention) interval. After the delay, two or more comparison stimuli, one of which is identical to the sample, are presented. A response to the matching comparison produces reinforcement, which is followed by an intertrial interval. A response to a nonmatching comparison leads directly to the intertrial interval. Over trials, the various sample stimuli occur equally often, and the spatial locations of the matching comparison are counterbalanced.

Two notable phenomena occur when samples consist of compounds of elements such as the orientation of a white line and color of background. First, Maki and Leith (1973) and others found that pigeons' matching accuracy was lower on line-orientation/color compound trials, with comparisons of either lines or colors, than on trials for which samples consisted of either lines or colors (but see Grant, 1982). Although these results suggested that the elements of the compound were selectively processed (Maki \& Leith, 1973), more recent interpretations have stressed perceptual degradation of the elements when they appear in compounds (Farthing, Wagner, Gilmour, \& Waxman, 1977) or generalization decrement arising from the difference between the sample and choice stimuli on compound sample trials (e.g., Cox \& D'Amato, 1982; Santi, Grossi, \& Gibson, 1982).

This research was supported by a Natural Sciences and Engineering Research Council of Canada (NSERC) operating grant to D.M.W. W. J. Jacobs is a NSERC University Fellow. C. Dumas, R. Wright, and $S$. Vessal assisted with the research. Send requests for reprints to Donald M. Wilkie, Department of Psychology, University of British Columbia, Vancouver, Canada V6T 1W5.
Second, control of matching accuracy by the elements of the compound is asymmetrical. Farthing et al. (1977) found that matching accuracy was superior when colorline compounds were followed by color comparisons than when they were followed by line comparisons. This suggested that forgetting of sample information may be more rapid for line stimuli (see also Nelson \& Wasserman, 1981). It is not yet known how general this asymmetry effect is in compound-sample DMTS procedures, and we are still unable to predict which of the elements will predominate. We undertook the present research to begin to provide more information relevant to such issues.

In the present experiments, we sought to determine which of two salient stimuli results in better matching accuracy. The compound samples consisted of a color, shown by Farthing et al. (1977) to be salient, and spatial location, a stimulus that readily controls pigeons' delayedmatching performance (e.g., Wilkie \& Summers, 1982). During the comparison period, the subjects were tested on the color (red or green) or the location (right or left key) dimensions of the compound.

\section{EXPERIMENT 1}

Here, we examined the acquisition of delayed matching to spatial-location/color compounds.

\footnotetext{
Method

Subjects. Three Silver King pigeons, maintained at about $85 \%$ to $90 \%$ of normal body weight, served. Bird 1 had extensive experience in DMTS experiments, the most recent of which involved red and green samples presented on the center key and red and green comparison stimuli presented on the side keys. Birds 2 and 3 were experimentally naive.

Apparatus. One wall of each of three conventional test chambers contained a grain feeder mounted below the center of a row of three translucent pecking keys. Each key was backed with a projector capable of projecting red, green, or yellow light. The left and right keys were about
} 
$25 \mathrm{~cm}$ apart. Data collection and experimental control were carried out by a Data General NOVA 3 computer operating under RDOS and the MANX language (Gilbert \& Rice, 1979).

Procedure. Birds 2 and 3 were trained to eat from the grain feeder when it was raised and illuminated and then were autoshaped to peck red and green on the center key. These birds, as well as Bird 1, were then given DMTS training.

The DMTS sessions consisted of 30 trials, separated by $15 \mathrm{sec}$ intervals. A random one-half of the trials began with red on the left key. The other trials began with green on the right key. Both samples lasted for $5 \mathrm{sec}$ and were followed by a 0.5 -sec delay spent in darkness. A random one-half of the delays were followed by red and green on the side keys, the right-left locations varying randomly across trials. On the other trials, both side keys were yellow. On the latter trials, a peck to the yellow side key that occupied the same location as the sample produced a 5-sec grain reinforcer, whereas a peck to the other yellow key produced only $5 \mathrm{sec}$ of darkness. When red and green appeared as choices, pecking red was reinforced after a red-left sample and pecking green was reinforced after a green-right sample. These conditions were maintained for 119 (Bird 1), 107 (Bird 2), and 132 (Bird 3) sessions.

\section{Results}

Figure 1 shows matching accuracy (proportion of trials on which the matching color on red-green comparison trials and matching location on yellow comparison trials were chosen) during early and late stages of acquisition. Clearly, the birds learned location matching more quickly than they learned color matching. This superiority was also apparent for Birds 2 and 3 at the end of acquisition, as shown by the last-week averages shown in Figure 1 .

\section{EXPERIMENT 2}

Here, performance on color- and location-matching trials was examined at three delay intervals.

\section{Method}

Subjects and Apparatus. The three pigeons and test chambers used in Experiment 1 also were used in Experiment 2. In addition, another DMTS-experienced pigeon and a fourth test chamber similar to the others were used.

Procedure. Sessions for Birds 1-3 were identical to those in Experiment 1 , except that three delay intervals $(0.5,2$, and $8 \mathrm{sec}$, each occurring with the same probability) were used. The procedure for Bird 4 was similar, except for the delays $(2,8$, and $16 \mathrm{sec})$. Birds $1-3$ received 72 sessions; Bird 4 received 198 sessions.

\section{Results}

Figure 2 shows matching accuracy on color- and location-matching trials as a function of the length of delay separating sample presentation and choice period. These data are averages over all sessions in Experiment 2 for Birds 1-3 and the last 100 sessions for Bird 4. Again, superior matching on location-matching trials was observed, although this superiority was small at the shorter delay intervals for Bird 1.

\section{EXPERIMENT 3}

There were two asymmetries in the procedures used in Experiments 1 and 2 that potentially could account for location superiority. The first was the presence of location competition on color test trials but the absence of color competition on location test trials. That is, on colormatching trials, choice of the correct color could be interfered with by competition from the location cues, whereas on location-matching trials, competition from the colors could not occur because red and green were not present as choice alternatives.

\section{BIRD 1}

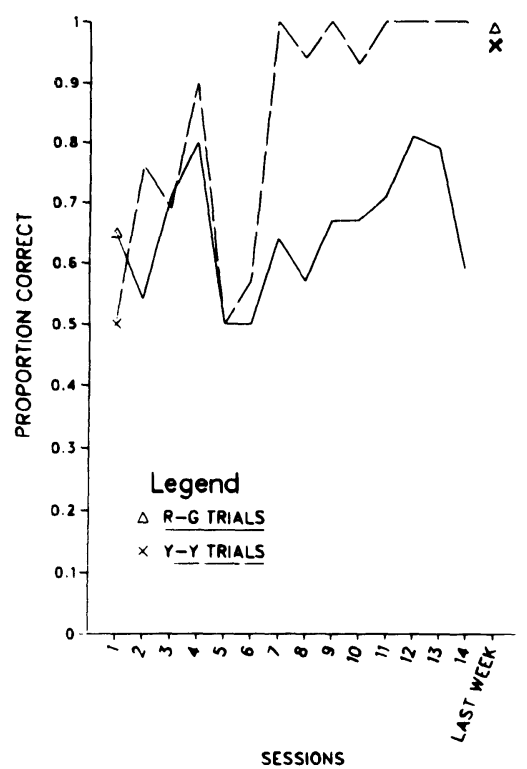

BIRD 2

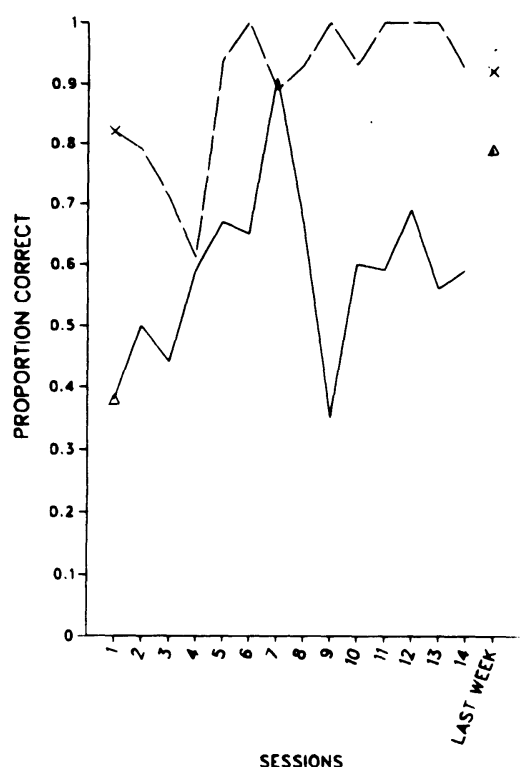

BIRD 3

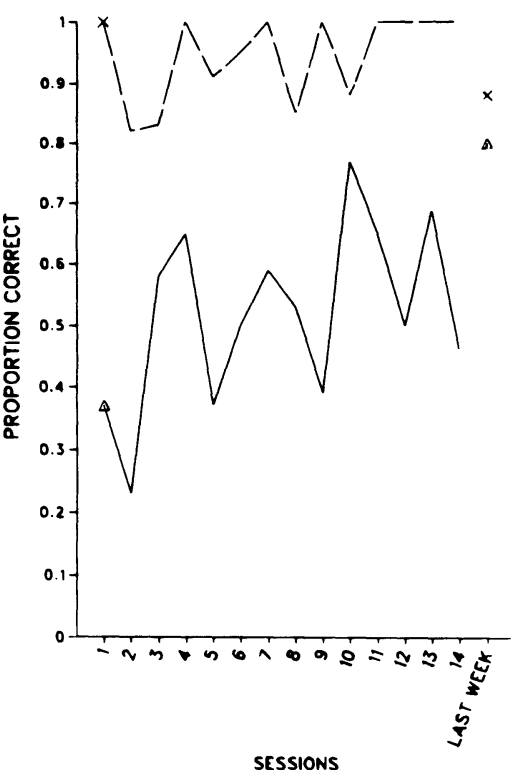

Figure 1. Proportion of trials in Experiment 1 on which the matching color (R-G trials) or matching location (Y-Y trials) was chosen during the first 14 sessions of acquisition. Also shown are averages for these two types of trials over the final week of acquisition. 
BIRD 1

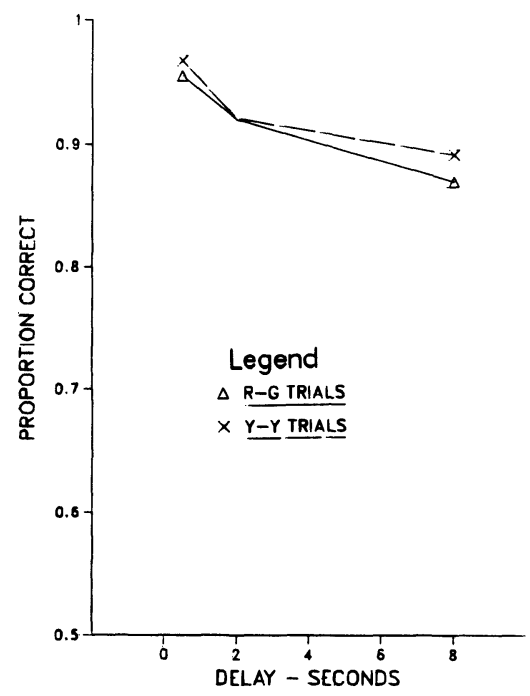

BIRD 3

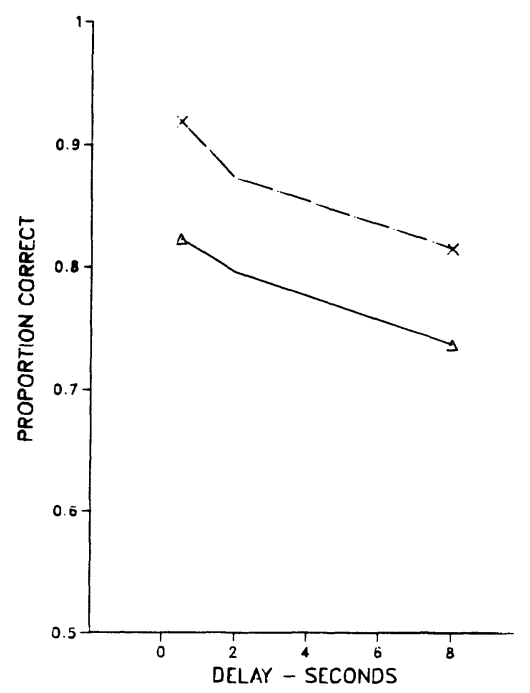

BIRD 2

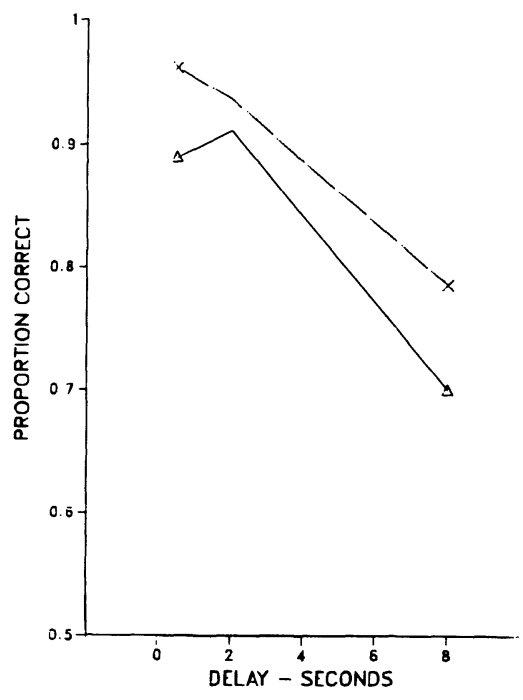

BIRD 4

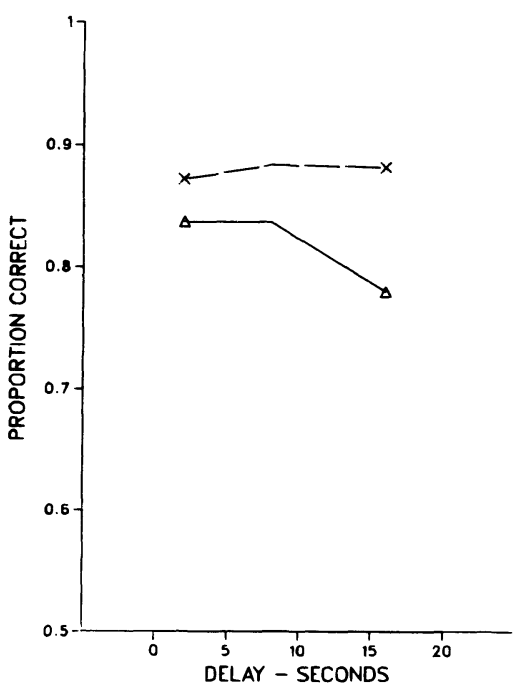

Figure 2. Proportion of trials in Experiment 2 on which matching color (R-G trials) or matching location (Y-Y trials) was chosen as a function of the delay separating sample presentation and choice period.

The second asymmetry was that there were twice as many location trials of each type as there were color trials of each type, because each color sample had two corresponding comparison trials, whereas each location sample had only one .

To discount these asymmetries as explanations for location superiority, the following procedures were implemented in the present control experiment. Samples continued to be red and green on the side keys, and color choices were presented as before. On location test trials, red and green also appeared, but flashed on and off at a rate of $10 \mathrm{~Hz}$. The right-left counterbalancing of red and green on the latter trial type ensured an equal number of trial types.

\section{Method}

Subjects. Two naive Silver King pigeons, Birds 5 and 6, were used. A third pigeon was discarded due to its failure to discriminate either color or location problems at above-chance levels.

Apparatus. The apparatus was the same as in Experiments 1 and 2.

Procedure. The birds were first trained to eat from the hopper and were then autoshaped to peck red on the left key and green on the right key: Red and green appeared equally often for a maximum of $10 \mathrm{sec}$ if no peck had occurred, and trials were separated by 30 -sec intervals.

The birds next received 26 MTS sessions. Sessions consisted of 60 trials, separated by $15-\mathrm{sec}$ intervals. On each trial, the probability was .5 that red on the left key would appear as the sample. Both samples appeared for $5 \mathrm{sec}$ and were followed by a .5 -sec delay interval. On a random one-half of the trials, the red comparison appeared on the right and the green on the left; on the other trials, the reverse order appeared. The probability was .5 on each trial that the choice stimuli flashed at $10 \mathrm{~Hz}$ (equal on and off times); on these trials, choice of the matching location 
was reinforced. On the other trials, the choices were steady, and choice of the matching color was reinforced.

During the final 21 sessions, flashing choice stimuli indicated that color was rewarded; steady choice stimuli indicated that location was rewarded.

\section{Results}

Figure 3 shows matching accuracy on color- and location-matching trials over blocks of two sessions. As in the first two experiments, matching accuracy on location trials was superior.

Location superiority was also apparent during the reversal stage of the experiment: During the final seven sessions, Bird 5 averaged $76 \%$ correct on location trials but only $65 \%$ correct on color trials; the corresponding scores for Bird 6 were $87 \%$ and $53 \%$ correct.

BIRD 5
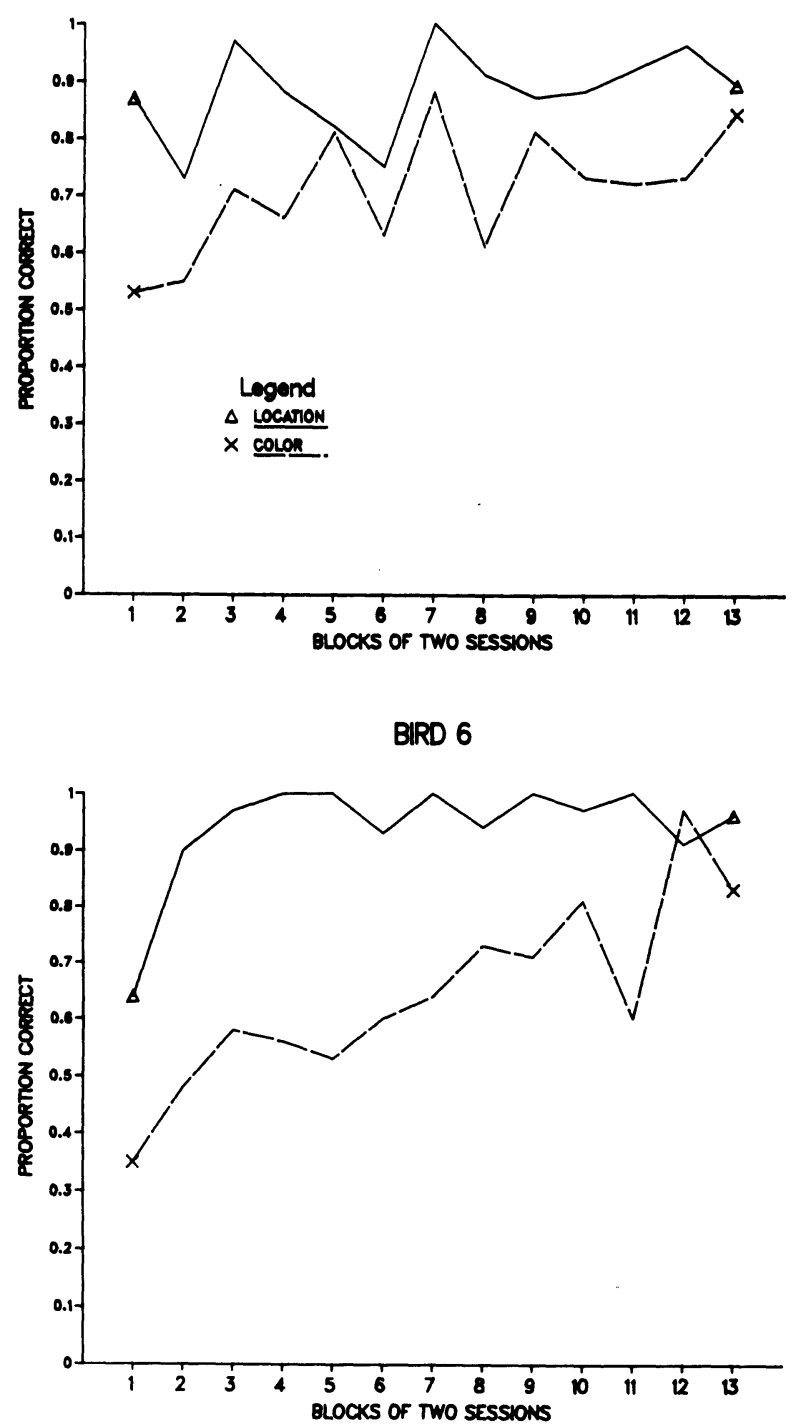

Figure 3. Proportion of trials in Experiment 3 on which matching color or matching location was chosen.

\section{DISCUSSION}

Clearly, matching is more accurate when birds choose a stimulus that matches location rather than color of the sample. This result, in conjunction with those reported by Farthing et al. (1977) and Nelson and Wasserman (1981), suggests that asymmetry effects are not uncommon in compound-sample DMTS.

Little is known about why some stimuli are more effective in controlling behavior. Often, appeals are made to "biological relevance", in attempting to account for stimulus asymmetry (e.g., Foree \& LoLordo, 1973; Spetch \& Wilkie, 1981), but such appeals are not reasonable here because both colors and location information seem to be biologically salient for the pigeon. An effect reported by Urcuioli and Honig (1980) may be more relevant in accounting for the present results. It has been known for some time that the cue properties of differential responding can serve as samples in matching problems (e.g., Lattal, 1975). Urcuioli and Honig suggested that response cues can overshadow the actual sample stimuli. In their experience, the cue properties of "slow" versus "fast" responding to the sample, rather than the actual samples of vertical versus horizontal line, seemed to control pigeons' choices. Although pigeons do not always approach and peck location samples (Wilkie, 1983), the cue properties of orientation to and looking at the right and left keys may have overshadowed red and green on these keys.

\section{REFERENCES}

Cox, J. K., \& D'Amato, M. R. (1982). Matching to compound samples by monkeys (Cebus apella): Shared attention or generalization decrement? Journal of Experimental Psychology: Animal Behavior Processes, 8, 209-225.

Farthing, G. W., Wagner, J. M., Gilmour, S., \& Waxman, H. M. (1977). Short-term memory and information processing by pigeons. Learning and Motivation, 8, 520-532.

ForeE, D. D., \& LoLoRDo, V. M. (1973). Attention in the pigeon: Differential effects of food-getting versus shock-avoidance procedures. Journal of Comparative and Physiological Psychology, 85, 551-558.

GILBERT, S. G., \& RICE, D. C. (1979). NOVA SKED II: A behavioral notation language utilizing the Data General Corporation real-time disk-operating system. Behavior Research Methods \& Instrumentation, 11, 71-73.

Grant, D. S. (1982). Prospective versus retrospective coding of samples of stimuli, responses, and reinforcers in delayed matching with pigeons. Learning and Motivation, 13, 265-280.

LATTAL, K. A. (1975). Reinforcement contingencies as discriminative stimuli. Journal of the Experimental Analysis of Behavior, 23, 241-246.

MAKI, W. S., JR., \& LEITH, C. R. (1973). Shared attention in pigeons. Journal of the Experimental Analysis of Behavior, 19, 345-349.

Nelson, R. R., \& Wasserman, E. A. (1981). Stimulus asymmety in the pigeon's successive matching to sample performance. Bulletin of the Psychonomic Society, 18, 373-346.

SANTI, A., Grossi, V., \& Gibson, M. (1982). Differences in matchingto-sample performance with element and compound stimuli in pigeons. Learning and Motivation, 13, 240-256.

SPETCH, M. L., \& WILKIE, D. M. (1981). Duration discrimination is better with food access as the signal than with light as the signal. Learning and Motivation, 12, 40-64.

URCuloli, P. J., \& HonIG, W. K. (1980). Control of choice in conditional discriminations by sample-specific behaviors. Journal of Experimental Psychology: Animal Behavior Processes, 6, 251-277.

WILKIE, D. M. (1983). Pigeons' spatial memory: II. Acquisition of delayed matching of key location and transfer to new locations. Journal of the Experimental Analysis of Behavior, 39, 69-76.

Wilkie, D. M., \& SUMmers, R. J. (1982). Pigeons' spatial memory: Factors affecting delayed matching of key location. Journal of the Experimental Analysis of Behavior, 37, 45-56.

(Manuscript received for publication November 29, 1984.) 